\title{
Assessing Farmers Attitude Towards Organic and Conventional Farming in Basona Worana District, Semen Shoa, Amara Region of Ethiopia
}

\author{
Gemechu Fufa Arfasa (M.Sc.) ${ }^{*} \quad$ Tizita Tesfaye \\ Jimma University, PO box 307, Jimma, Ethiopia
}

\begin{abstract}
Farming is a part of agriculture by which people known as 'Farmer' grow crops and keep animals to help them in cultivating the crops for them. There has been a constant debate on organic vs conventional farming system by various experts and also by the farmers performing the systems (Hazell and Wood, 2008). This paper also aims to compare the farmers attitude towards the two farming systems, whether or not they know about the advantages and disadvantages of the farming systems, to identify which system they perform, and to sort out whether they are reasonable or not about the system which they are performing. To do so, a total of 36 households were selected by simple random sampling from the study area. The results depict that the majority (\%) of the respondents interviewed are using both organic and conventional farming systems in integration (i.e. organic fertilizers like: compost and animal manures with commercial/synthetic fertilizers); while the minority (\%) of the farmers perform conventional agriculture and none of the farmers perform organic farming system solely with most of the farmers are reasonable of the system which they are performing. It was also found out that almost all of the farmers are aware of the advantages and disadvantages of the farming systems which are identified scientifically, except some arguments which are addressed on the conclusion section.
\end{abstract}

Keywords: Organic, Conventional Farming

DOI: $10.7176 / \mathrm{JRDM} / 58-03$

Publication date: August $31^{\text {st }} 2019$

\section{INTRODUCTION}

\subsection{Background}

Survival of living things on the earth is impossible without cultivating food for their living purpose. Farming is a part of agriculture by which people known as 'Farmer' grow crops and keep animals to help them in cultivating the crops for them. Centuries ago, with the existence of life on the earth, farming became the earning source along with covering the needs of food. Initially it started on domestic level and then international level (Hazell and Wood, 2008). Later on, it became the trade among countries from all over the world via import and export. The world is full of different professions and made up of various human interventions for the survival of life. The production and management of farms and cultivation of food is mandatory to fulfill the need of human beings. There has been a constant debate on organic vs conventional farming system by various experts and also by the farmers performing the systems (Hazell and Wood, 2008).

Conventional crop production uses large quantities of chemical pesticides and fertilizers. They are harmful to the environment as they kill beneficial insects and pollute soil and water. In the organic farming, the absence of chemical sprays and increased biodiversity result in a better eco-balance between pests and beneficial insects. Chemical pesticides can cause poisoning as well as long term effects on human health (Altieri, 2004, Pearson, 2007). Whereas organic farming is free of chemical pesticides and produces safe and healthy food crops. Frequent use of chemical fertilizers and narrow crop rotation can cause declining soil fertility, while organic farming improves soil fertility through rotating leguminous crops like chickpea and field pea (Pearson 2007). Productivity and profitability persist to be the two most important indicators in assessing the success or failure of crop production. But high levels of productivity (though not necessarily profitable) have been and continue to be achieved through heavy use of energy-based cultural inputs together with fertilizer-responsive high-yielding crop varieties, farm mechanization which facilitates timeliness of field operations, and irrigation which help the crop from any yield-depressing effect of water deficit during the sensitive growth stage (Mendoza, 2002).

Organic farming is one of the widely used methods, which is thought of as the best alternative to avoid the ill effects of chemical farming. It is defined as 'a system that is designed and maintained to produce agricultural products by the use of methods and substances that maintain the integrity of organic agricultural products until they reach the consumer (Shennan, 2008). This is accomplished by using substances, to fulfill any specific fluctuation within the system so as to maintain long term soil biological activity, ensure effective peak management, recycle wastes to return nutrients to the land, provide attentive care for farm animals and handle the agricultural products without the use of extraneous synthetic additives or processing in accordance with the act and the regulations in this part. The origin of organic farming goes back, in its recent history, to 1940s. During this period, the path breaking literature on the subject published by J.I. Rodale in the United States, Lady Balfour in England 
and Sir Albert Howard in India contributed to the cause of organic farming (Bhagwat et al., 2008).

Modern agricultural farming practices, along with irrational use of chemical inputs over the past four decades have resulted in not only loss of natural habitat balance and soil health but have also caused many hazards like soil erosion, decreased groundwater level, soil salinization, pollution due to fertilizers and pesticides, genetic erosion, ill effects on environment, reduced food quality and increased the cost of cultivation, rendering the farmer poorer year by year.

Numerous studies have attempted to investigate farmers' knowledge and attitudes towards fertilizers (Enyonget et al., 2000). Among these studies several have attempted to explain the attitudes of farmers belonging to different groups. Farouque and Takeya (2007) assessed farmer's attitudes in different samples based on land holder (landless or holding marginal, small, medium sized or large farms). Similarly, Alam et al., (2003) also assessed farmers attitudes towards four different farm sizes according to land holder class (marginal, small, medium sized and large farms), and he assessed farmers attitudes in the high lands and low lands of the Maniac District, Mozambique. However, little research has explored farmer's knowledge of fertilizers. Zhou et al., (2003) studied farmers' knowledge of the chemical fertilizers in Northern part of Ethiopia; and he recently studied farmers' knowledge of organic fertilizers use in the Northern Agricultural zone. Based on previous studies, it is widely accepted that information about farmer's knowledge and attitudes towards such agricultural practices would provide a better understanding of how to encourage farmers to implement cropping strategies and to improve their delivery approaches.

\subsection{Statement of the Problem}

In fact nothing is perfect in this world. So both systems of farming have their own advantages and disadvantages. Organic farming for example has the advantages like: improvement of structure of soil; tt uses wastes and residuals; it reduces the ground water pollution (Forman et al., 2012); it has less environmental effects than conventional ones. However, it has also its own shortcomings like: decay of organic matter is slower. it is not good for the growth of plants; High amount of labor input are required; manures can pollute the water; it reduces production per unit of land.

On the other hand the conventional one has also advantages of increasing production per unit of land; increasing the yield level of crops and making the farmers capable of cope up with the increasing population. It also has disadvantages of harming the soil; pollution of surface water and groundwater, hazards to human and animal health, and damage to wildlife (Rosenthal and Matteo, 2001).

While numerous studies have been conducted in Ethiopia to identify the above advantages and disadvantages of the two farming systems and to examine the determinants and the resulting economic impact of chemical fertilizer, improved seeds, and physical conservation structures (Dercon and Christiansen, 2007; Kassie et al., 2008), no attempt has been made to comparatively analyze farmers perception of organic and conventional farming in the country in general and in the study area, in particular. Therefore, this research paper will be conducted to examine the farmer's perception towards the above mentioned two farming systems

\subsection{Research Objective}

1.3.1. General objective

The overall objective of this study was to assess the perception of farmers towards organic and conventional farming systems in Bassona Werenna district.

\subsubsection{Specific objectives}

The specific objectives include:-

$\checkmark$ To assess the farmers awareness towards the advantages and disadvantages of the two farming systems;

$\checkmark$ To assess the farmers' preference among the two farming systems;

$\checkmark$ To assess the reason of farmers to choose among the two farming systems.

\subsection{Research Question}

In order to address the objective of this study, the following research questions were formulated:

$\checkmark$ What is the farmer's attitude towards organic and conventional farming systems?

$\checkmark$ What are the reasons which force the farmers to choose among the two farming systems?

$\checkmark$ Which farming system do the farmers prefer among the two farming systems?

\subsection{Significance of the study}

This issue has importance because, almost no research related to the issue undertaken in the study area. Various studies have been carried out on issues like economic impact of chemical fertilizer, improved seeds, and physical conservation structures, but there was no any study which identified farmers' choice and reason of choice of the farming system. Therefore, this study will play a significant role in identifying farmer's attitude towards the two farming systems. This study is important not only for farmers but it will also promote understanding up on decision 
makers, concern bodies or stakeholders and government about the issue. It will provide constructive suggestion and recommendation for government, NGO, and local community to identify the farmers' perception towards the organic and conventional farming systems.

\section{LITERATURE REVIEW}

\subsection{Concepts and definition of organic farming system}

The ecological impacts of CA have been called into question, allowing for the emergence of organic agriculture $(\mathrm{OA})$ as an alternative approach to farming. OA is seen as a holistic approach to food production, basing its principles of practice on sustainability by focusing on the importance of long-term ecosystem health by excluding or limiting the use of conventional fertilizers, pesticides and GMOs (Pimentel et al., 2005). Because of the strict limitations on OA, many regulatory bodies exist to ensure that organic farms uphold to certain standards in order to sell their products as certified organic. The demand for sustainably farmed and chemical-free foods has provided organic foods with a price premium.

OA has had to adapt to maintain yields that are competitive with CA yet remain in line with its sustainability principles. Many farming techniques used by organic farmers have come about as a method of remaining competitive while adhering to the organic farming standards placed upon them (Cranfield et al., 2009, Grey, 2000). One common concern with farming is the gradual depletion of soil nutrients and soil organic carbon with each passing year of growth on farmland. Where CA would apply conventional fertilizers abundant in nutrients and organic carbon, OA relies on techniques such as crop rotation and the application of manures.

An organic farmer can opt to use animal manures which retain nutrients more effectively and reduce overall runoff (Pote et al., 2003), or the farmer can choose to plant leguminous cover crops in a crop rotation to fix nitrogen and replenish its bioavailability in the soil (van Kessel and Hartley, 2000). Unfortunately, legumes may present competition for resources. Crop residues from previous growths may be cycled back into the soil as another alternative to the use of conventional fertilizers. In the case of phosphorus and potassium, organic farmers may also use mineral powders from rock phosphate and potash to provide the two remaining macronutrients, respectively (Pelletier et al., 2008).

Typically, OA tills the soil as a method of weed suppression and control as well as for soil nutrient rotation (Barberi, 2002) provided from one of the alternative sources discussed above. Other methods organic farmers may use to physically control weeds include standard mowing or flame weeding to burn weeds and their seeds (Perruzzi et al., 2007). Badgley et al., (2007) argued that OA can feed the world yet it was counter-argued in a response that tillage in OA of corn is observed to be more detrimental to the condition and nutrition of the soil. This difference in the utility of tillage in OA is just one example of how little is known of its potential as a farming system to feed the world. Pests cannot be addressed with the exclusive use of pesticides in OA; leaving organic farmers to use integrate multiple approaches to pest control in what is now known as Integrated Pest Management (IPM). IPM aims to control pest populations through constant crop monitoring to maintaining healthy crops and avoid diseased crop plants and physical involvement with pest removal on the crops. In worst-case scenarios, minimal amounts of chemical pesticides are used after having tried biological controls in the form of other organisms or natural plant compounds to deter pests (US EPA, 2011). These practices demonstrate that OA is centered on sustainability and long-term health.

OA farms are typically associated with Farmer's Markets and Community Shared Agriculture movements, shortening the food chain and illustrating the relationship between the farm and the plate (Cone and Myhre, 2000, Dupuis and Gillon, 2009, Grey, 2000, Smithers et al., 2008). However, achieving the same yield as a CA system requires much more energy input per unit of land or per unit of yield, energy input that would typically come in the form of time or human labour. OA commands a higher price premium than CA because of its appeal to consumers who desire chemical-free foods and because of the labor costs associated with the farming efforts required (Jansen 2000). So while OA may provide a much more ecologically sound approach to agriculture, with minimal use of GHG-emitting machines and long-term natural farming strategies, it is still lagging in its competitive ability to yield enough food to feed the growing population at an affordable rate (Connor, 2007).

\subsection{Concepts and definition of conventional agriculture}

Modern agriculture has been working within the global food system to feed the world's urbanized masses via a gamut of advents in farming practices (Fraser et al., 2005) to become what is now known as industrial agriculture. The mass production of food through the techniques that define modern agriculture has led to the conventionalization of agriculture in a technocratic approach to agriculture (Fraser, personal communication).

The intensive farming that characterizes modern agriculture uses a higher amount of labor and chemicals per unit area than any other approach to farming. Much of this labor is mechanized to allow for a much more efficient use of land, providing a higher yield-output to human labor-input ratio. However, this conventional and mechanized form of agriculture is extremely energy intensive, requiring fossil fuels to power the machines that allow humans to farm on such a large scale (Pimentel et al., 1973, Pimentel et al., 2005). 
One of the defining methods that CA employs is the use of conventional fertilizers (Crews and Peoples 2004). Applied conventional fertilizers come in various standard N-P-K ratios for application on a crop. Fertilizers provide renewed applications of nutrients onto the soil, effectively removing consider long-term strategies to retain and replenish soil nutrient and soil organic carbon. Fertilizers are also the cause of one of the primary concerns of CA. Methane and nitrous oxide emissions are respectively the second and third most important GHGs after carbon dioxide (UNESCO-SCOPE 2007), and their emissions from agricultural fields has been greatly increased with the application of ammonium-based Environmental problems that have arisen from the use of conventional fertilizers highlight the disjunction between intensive industrial farming and care for natural ecosystem processes. For example, conventional fertilizers are used to provide an abundant amount of nutrients in biochemically available forms, but the scale at which fertilizers are applied coupled with the natural water cycle has led to nutrient-loaded runoff that feeds into aquatic systems (Goetz and Zilberman, 2000). The loss of dissolved oxygen driven by nutrient-laden waters has led to the Eutrophication of coastal regions and lakes throughout North America, altering ecosystem dynamics of entire aquatic systems (Carpenter et al., 2009).

The post-World War II Green Revolution produced another example showcasing the large divide between CA development and environmental considerations. The first suite of synthetic pesticides was produced, leading overtime to the refined synthesis and common applications of pesticides to eradicate pest insects, weeds, and other undesired organisms. Pesticides are used to control natural biological processes that disrupt the homogeneity and production efficiency of industrial crop farms by disrupting the natural chemical functions (Hussain et al., 2009) of unwanted organisms in the farm system. The problem herein lies in the chemical selectivity of the pesticides and the biological evolution of tolerance and resistance to these pesticides, rendering them ineffective and biochemically obsolete. Furthermore, human consumption of foreign and synthetically produced chemicals is an aspect of agriculture that the general public is none to comfortable with (Dunlap and Beus 1992).

The introduction of GMOs presented a technocratic solution to the biological problems associated with excessive pesticide use. GMOs gave farms the ability to grow masses of phenotypically and genotypically monocultured crops, fitting into the CA system by allowing the creation of machines specialized to handle vast quantities of single crop types. Such a precise specialization of crops delivers an even higher yield output per unit of energy input (Gardner 2003), resulting in less land required for farming and leaving more natural land intact.

As a whole, the mechanization of farming in today's conventionally industrial agriculture has brought about an approach to farming that is disconnected from the earth and the people it feeds. The growing number of links in the food chain renders it harder and harder to see firsthand the ecological impacts that conventional farming has (Cone and Myhre 2000), facilitating the ease with which we can forget its connection to climate change and food security.

\subsection{Comparison of organic and conventional agriculture based on various issues 2.3.1. Soil quality}

Multiple studies of long-term field trials have demonstrated a strong positive impact of organic and diversified farming practices on the enhancement of key soil quality indicators (Bengtsson et al., 2005, Pimentel et al., 2005, Fliessbach et al., 2007). In particular, surface soils under organic management with high residue return rates or organic matter inputs generally have higher levels of soil organic matter (Franzluebbers 2004, Kong et al., 2005, Marriott and Wander 2006). Improved levels of soil organic matter generally enhance soil quality with respect to ten critical and interrelated functions within agro ecosystems: biogeochemical cycling and retention of nutrients, soil aggregate formation and stability, water infiltration and water-holding capacity, decontamination of water, $\mathrm{pH}$ buffering, erosion reduction, and promotion of plant growth (Mäder et al., 2002, Weil and Magdoff 2004). Organic management can increase soil organic matter through recycling of crop residues and manure, green manuring, cover cropping, vegetated fallow periods, and the addition of compost. Using various indicators of soil organic matter in a quantitative synthesis of nine long-term study systems in the United States, Marriott and Wander (2006) found that organic systems with legume cover crop rotations had significantly higher soil organic matter in surface soils than did paired conventional systems, irrespective of whether the organic treatment included manure.

\subsubsection{Nutrient management}

Various diversified (organic) farming system practices increase the uptake of nutrients into crop biomass and/or soils, thus enhancing fertilizer use efficiency while reducing loss of nutrients to air and water, which are two critical agronomic and environmental management goals. Conventional agricultural systems, especially grains, have experienced dramatically declining fertilizer use efficiencies over several decades, requiring large increases in synthetic fertilizer application rates simply to maintain yields, with attendant increases in nutrient loss (Tilman et al., 2002, Miao et al., 2011). Loss of agricultural nitrogen and phosphorus to air and water cause severe environmental and human health problems, including Eutrophication of fresh and marine waters, the emission of greenhouse gasses, and the depletion of stratospheric ozone (Tilman et al., 2002, Townsend et al., 2003, Diaz and Rosenberg 2008, Park et al., 2012). Thus diversified farming system practices can contribute simultaneously to efficient use of nutrients and to mitigation of point-source pollution. 
In comparing organic agriculture with conventional agriculture, Mondelaers et al., (2009) found, significantly lower nitrate leaching for organic farming systems. The main drivers behind higher nitrate leaching in conventional farming systems include greater application rates of concentrated soluble fertilizers, lower use of cover crops that can scavenge residual soil $\mathrm{N}$, lower $\mathrm{C}$ to $\mathrm{N}$ ratio of fertilizers, and higher animal stocking densities per hectare (Mondelaers et al., 2009, Brennan and Boyd 2012). However, these results were heterogeneous; possibly due to among-study differences in soil type, farming system, region, study method, and time of measurement, and, according to the authors, should be interpreted cautiously. Furthermore, while mean values of nitrate leaching from organic fields were less than half that of conventional, the two systems demonstrated near equivalence in nitrate leaching per unit of yield (due to the higher yields measured on conventional fields). In the same analysis, Mondelaers et al., (2009) found no significant differences in phosphorus loss between organic and conventional farming systems $(\mathrm{N}=12)$. However, because phosphorus has low solubility and is primarily transported on soil particles, the demonstrated lower rates of soil erosion in diversified farming systems might result in reduced phosphorus pollution of surface waters (Tilman et al., 2002).

\subsubsection{Water-holding capacity}

The positive impact of diversified farming practices on soil organic matter content (Marriott and Wander 2006) can also lead to higher available water for plants (available water capacity) in surface soils, which may positively influence resistance and resilience of crop plants to drought conditions (Lotter et al., 2003, Weil and Magdoff 2004, Liu et al., 2007). Hudson (1994) has shown that in all soil texture groups, as soil organic matter content increased from 0.5 to $3 \%$, available water capacity more than doubled. In long-term trials measuring the relative water-holding capacity of soils, diversified farming systems have shown a clear advantage over conventional farming systems. For example, in a 37-year trial, Reganold et al., (1987) found significantly higher soil organic matter levels and $42 \%$ higher surface soil moisture content in organically managed plots than in conventional plots. In a 21-year study in Switzerland, Mäder et al., (2002) reported 20 to 40\% higher water-holding capacity in organically managed soils than in conventionally managed soils. Recent research has suggested, however, that prior studies have not adequately measured the effects of agricultural practices like no-till and organic farming on soil organic matter in deeper soil layers (Dolan et al., 2006, Kravchencko and Roberts 2011, Syswerda et al., 2011). Therefore, although organic and no-till farming systems have clear advantages for soil organic matter accumulation (and thus water-holding capacity) in surface soils (Franzluebbers 2004, Marriott and Wander 2006), additional sampling at greater soil depths is an important, priority research area.

\subsubsection{Energy-use efficiency and reduction of global-warming potential}

Over the last 15 years, many attempts have been made to measure the global-warming potential of conventional and diversified farming systems by calculating relative energy use, energy-use efficiency, and the outputs of key greenhouse gasses including carbon dioxide (CO2), methane (CH4), and/ or nitrous oxide (N2O) (Lynch et al., 2011). In a major review of approximately 130 studies, Lynch et al., (2011) analyzed farm-level energy use and global-warming potential of organic and conventional farming systems, including field, fruit, and vegetable crops, and beef, hog, poultry, and dairy production. In general, organic farming systems had significantly lower energy use and greenhouse gas emissions per hectare, and higher energy efficiency (energy input/output) per unit of product. These differences exceeded, often by a substantial margin, the $20 \%$ threshold set by the authors as a minimum level needed for policy action. Avoidance of synthetic nitrogen fertilizers, which require large amounts of energy to produce (Pelletier et al., 2011), and lower use of feed concentrates, were largely responsible for the improved energy performance of the organic farming systems per unit of land or product. Results were more variable for global-warming potential than for energy indicators, however, due in part to large uncertainties in the measurement of $\mathrm{N} 2 \mathrm{O}$ emissions from soils and manure. In some studies, especially those of hog, poultry, and dairy production, organic methods produced higher emissions per unit of product, often due to lower rates of feed conversion. Contrary to expectations, increased tillage in organic farming systems for weed control and crop rotations was not a significant contributor to on-farm energy use, nor did these practices lead to net reductions in soil carbon, due to the mitigating effects of green manures (Lynch et al., 2011).

\subsubsection{Crop yield}

Badgley et al., (2007) conducted a quantitative synthesis of studies measuring the relative yields of organic and conventional farms across many cropping systems. In developed nations they found that crop yields were $8.6 \%$ lower for organic systems than for conventional systems (with a 95\% confidence interval of 4.7 to $12.5 \%$, based on 138 comparisons in 43 studies). In developing nations, they found a mean yield increase of $174.6 \%$ (with a $95 \%$ confidence interval of 156.0 to $191.2 \%$ ) when diversified farming practices were employed, compared with resource-poor (generally subsistence) farming strategies (138 comparisons from 29 studies). These results were contested, however, by authors who suggested that organic management would produce similar yields only if offfarm sources of manure were utilized, or when utilizing leguminous noncrop rotations that would decrease overall yields over the full crop rotation cycle (Kirchmann et al., 2008). Subsequently, two new studies (de Ponti et al., 2012, Seufert et al., 2012) critiqued the Badgley et al., (2007) study, primarily based on the choice of studies included in the Badgley study. Based on data quality criteria and a stricter definition of organic and conventional 
systems, De Ponti et al., (2012) rejected $86 \%$ of the studies utilized by Badgley et al., (2007); in their quantitative synthesis, they found an average $20 \%$ (with a $95 \%$ confidence interval of 17.8 to $22.2 \%$ ) yield gap (based on 362 comparisons from 135 studies post 2004). Seufert et al., (2012) conducted a meta-analysis utilizing an overlapping but different set of studiesthan those used by de Ponti et al., (2012). While also requiring a strict definition of organic versus conventional, the meta-analysis further required that studies report both a mean and error term, resulting in 316 comparisons from 66 studies. Seufert et al., found an overall yield gap of $25 \%$ (with a $95 \%$ confidence interval from 21 to 29\%) (Seufert et al.,2012). L. Ponisio and C. Kremen (personal observation) noted that Seufert et al., (2012) used some yield data as the baseline for multiple comparisons (more than 50\% of observations), which might result in an overestimate of the size and significance of differences between organic and conventional yields. The question of how organic and conventional yields compare is still uncertain due to the small number of available studies that present appropriate data for making this comparison; this is a key area for additional research.

Conclusions varied widely among the de Ponti et al., (2012), Seufert et al., (2012), and Badgley et al., (2007) studies regarding differences in yield gaps among developed and developing countries. Most of the data in the Seufert et al., and de Ponti et al., analyses were from the developed world (80 to 90\%), whereas the Badgley et al., (2007) study included a larger proportion of responses from developing countries (45\%). Seufert et al., found a significantly greater yield gap for developing (43\%) than developed (20\%) countries, whereas de Ponti et al., found a slight, but non-significant, reduction in yield gap for developing countries relative to developed. Seufert et al., attributed their finding of a larger yield gap in developing countries to the atypically high conventional yields found in those studies, relative to local averages. In contrast, Badgley et al., found a large yield gain for organic systems in developing countries (174\%). The switch from yield gain to yield loss between the Badgley et al., and the other studies can be attributed to the different ways in which each study drew comparisons among farming systems. The two recent papers utilized strict definitions of organic and conventional systems. In contrast, Badgley et al., compared resource-conserving agro-ecological methods that were not necessarily strictly organic against subsistence or low-input conventional systems, rather than against high input conventional methods. The results in Badgley et al., therefore imply that widespread implementation of diversified farming systems by smallholders in developing countries might result in substantial gains for global food production because, by one estimate, $50 \%$ of smallholders in developing nations do not currently use resource-conserving practices (Altieri and Toledo 2011). However, many of the studies from developing countries utilized by Badgley et al., (2007) lacked appropriate controls, and therefore we lack a strong quantitative assessment of the potential for diversified farming systems to enhance food production in developing countries (Seufert et al., 2012).

\subsubsection{Labor and employment}

Organic production is more labor-intensive than conventional production. On the one hand, this increased labor cost is one factor that makes organic food more expensive. On the other hand, the increased need for labor may be seen as an "employment dividend" of organic farming, providing more jobs per unit area than conventional systems. The 2011 UNEP Green Economy Report suggests that "an increase in investment in green agriculture is projected to lead to growth in employment of about 60 per cent compared with current levels" and that "green agriculture investments could create 47 million additional jobs over the next 40 years."The United Nations Environment Programme (UNEP) also argues that "by greening agriculture and food distribution, more calories per person per day, more jobs and business opportunities especially in rural areas, and market-access opportunities, especially for developing countries, will be available.

\subsubsection{Biodiversity}

The conservation of natural resources and biodiversity is a core principle of organic production. Three broad management practices (prohibition/reduced use of chemical pesticides and inorganic fertilizers; sympathetic management of non-cropped habitats; and preservation of mixed farming) that are largely intrinsic (but not exclusive) to organic farming are particularly beneficial for farmland wildlife. Using practices that attract or introduce beneficial insects, provide habitat for birds and mammals, and provide conditions that increase soil biotic diversity serve to supply vital ecological services to organic production systems. Advantages to certified organic operations that implement these types of production practices include: 1) decreased dependence on outside fertility inputs; 2) reduced pest management costs; 3) more reliable sources of clean water; and 4) better pollination (Gabriel et al., 2010, Batáry et al., 2011).

Nearly all non-crops, naturally occurring species observed in comparative farm land practice studies show a preference for organic farming both by abundance and diversity. An average of $30 \%$ more species inhabits organic farms. Birds, butterflies, soil microbes, beetles, earthworms, spiders, vegetation, and mammals are particularly affected. Lack of herbicides and pesticides improve biodiversity fitness and population density (Jackson et al., 2009). Many weed species attract beneficial insects that improve soil qualities and forage on weed pests. Soilbound organisms often benefit because of increased bacteria populations due to natural fertilizer such as manure, while experiencing reduced intake of herbicides and pesticides. Increased biodiversity, especially from beneficial soil microbes and mycorrhizae have been proposed as an explanation for the high yields experienced by some 
organic plots, especially in light of the differences seen in a 21-year comparison of organic and control fields (Kremen et al., 2002, Chaplin-Kramer et al., 2011).

Biodiversity from organic farming provides capital to humans. Species found in organic farms enhance sustainability by reducing human input (e.g., fertilizers, pesticides) (Gabriel et al., 2010).

A wide range of organisms benefit from organic farming, but it is unclear whether organic methods confer greater benefits than conventional integrated agri-environmental programs. Organic farming is often presented as a more biodiversity-friendly practice, but the generality of the beneficial effects of organic farming is debated as the effects appear often species- and context-dependent, and current research has highlighted the need to quantify the relative effects of local- and landscape-scale management on farmland biodiversity (Batáry et al., 2010). There are four key issues when comparing the impacts on biodiversity of organic and conventional farming: (1) It remains unclear whether a holistic whole-farm approach (i.e. organic) provides greater benefits to biodiversity than carefully targeted prescriptions applied to relatively small areas of cropped and/or non-cropped habitats within conventional agriculture (i.e. agri-environment schemes); (2) Many comparative studies encounter methodological problems, limiting their ability to draw quantitative conclusions; (3) Our knowledge of the impacts of organic farming in pastoral and upland agriculture is limited; (4) There remains a pressing need for longitudinal, systemlevel studies in order to address these issues and to fill in the gaps in our knowledge of the impacts of organic farming, before a full appraisal of its potential role in biodiversity conservation in agro ecosystems can be made (Holzschuh et al., 2008).

\section{RESEARCH METHODOLOGY}

\subsection{Study area description}

\subsubsection{Location}

The study was conducted in Bassona Worenna District of north Shewa Zone central Ethiopia. Geographically, the study area is located in north eastern $141 \mathrm{KM}$ from Addis Ababa and $11 \mathrm{KM}$ away from Debre Berhan city. It is located approximately 9011 'north latitude and 390 45' east longitudes and an altitude of 2872 meter above sea level (BKAAO, 2009). The specific study area for this research is shows that in map sit in BassonaWorena District of North Shewa Zone.

\subsubsection{Climate}

The geological zonation of the area is in Dega $(80 \%)$ and Weynadega $(20 \%)$. The mean annual Temperature is between the range 100c-200c. The study area has sometimes bimodal rain season. The short rain generally arrived mid to late February while the long rain begin late June and continue to the September. The mean annual rain fall in average value is $955.3 \mathrm{~mm}$ per year (BKAAO, 2009).

\subsubsection{Population}

Bakilo Kebele is one of widely populated kebele of Bassona worenna District in north Shewa Zone with the total population of 5404 of which 2676 are males and 2728 are females and it consists of 1213 households from those $876(72.2 \%)$ are headed by male and the rest $337(27.8 \%)$ are headed by females (population and housing census, 2009)

\subsubsection{Socio-Economics}

The farming system in Bakilo kebele is mixed farming system which means: crop production, cash crop, and animal raring. Under rainy season, the main crop types that commonly grow are cereals crops, cash crop, and livestock production farms. The main livelihood strategy for the majority of population are annual and perennial crop including cereals, cash crops, vegetables, fruit (tomato, onion, carrot)are grown the major livestock ranging includes castles, horse, donkey, and other community would participate on different works which they produce income for their livelihood. Around Bakilo kebele some streams would exist which are suitable for irrigation development.

\subsubsection{Topography and Soil types}

The topography of Bakilo kebele land is varies from undulated land escape and it is more or less flat. The kebele comprises many scattered plantation forest but not natural. The altitude of study area is 2872 meter above sea level (kebele administration agricultural office). The major types of soil that found in Bakilo kebele is brown $(60 \%)$, red $(10 \%)$ and black (30\%).

\subsubsection{Current Land use and Land cover}

The total area of land in Bakilo kebele is 4230.75 ha from those hectares consists mainly 2243ha annual crop, 365.9ha of plantation forest, 1231.35ha range land and different construction service and other stony land, and the rest 390.5ha irrigation land. The main agricultural productions in the study area are wheat, barley, bean and other cereals. The most dominating land use types are farm and grazing land.

\subsection{Data type}

The sources of data we used in the study area were both primary and secondary sources. Among primary sources: field observation, household survey, and interview were used. Secondary information relevant to this study were 
collected from different sources including published and unpublished materials, books, journals, articles, reports, and electronic websites.

\subsection{Sampling technique}

In order to get necessary data from the respondents, we used simple random sampling. We selected this technique to give equal chance for all of the respondents. Therefore, all of the respondents have an opportunity to be selected. By using this technique, thirty six respondents were selected randomly among the total population of 1213 by using random number.

\subsection{Sample size}

According to the demographic data of Bakilo Kebele, there were 1213 households in the study area. Due to shortage of time and finance, we decided to take the sample of $3 \%$ of households out of the total population. Therefore, based on the following formula, our sample size out of 1213 households was:-

$$
\mathrm{SS}=\mathrm{THH}^{*} \%
$$

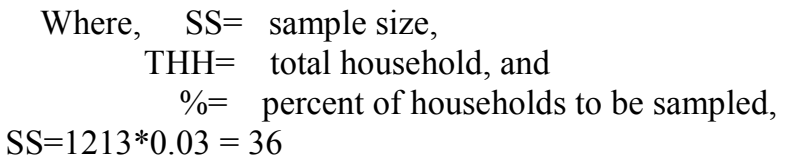

\subsection{Data collection methods}

Both primary and secondary data were used for this study. The primary data collection was started with a preliminary survey followed by household survey with questionnaires.

Secondary information relevant to this study was collected from different sources including published and unpublished materials, books, journals, articles, reports, and electronic websites.

A closed and open ended questionnaire and checklists for interview was developed.

\subsubsection{Preliminary survey}

First preliminary survey was done which comprised field observation, informal discussion with administrative officers and representatives of the local people to have better knowhow about the area.

\subsubsection{Household survey}

Structured and semi- structured questionnaires were prepared for the household survey based on the information elicited through preliminary survey. The household questionnaire was contained questions on demographic and socio-economic conditions, perception of local community towards the advantages and disadvantages of farming systems, their favorite among the two, and why they chosen that farming system.

\subsection{Data analysis method}

The data which was collected from primary source by using interviews and direct observation were coded and tabulated and inserted on excel. Simple descriptive statistical tools such as percentage, mean, and frequency were used for analysis of quantitative data while narration was used for qualitative data analysis. Finally, results observed from the analysis were presented in the form of table, chart and graph.

\section{RESULT AND DISCUSSION}

\subsection{Socio-economic and demographic characteristics of respondents}

The socio-economic characteristics analyzed in this paper are age, sex, marital status and educational level of the respondents. 
Table 1: Analysis of socio-economic and demographic data of the respondents

\begin{tabular}{|c|c|c|c|c|}
\hline \multirow[t]{2}{*}{ No. } & \multicolumn{2}{|c|}{ Personal information } & \multirow[t]{2}{*}{ Number of respondents } & \multirow[t]{2}{*}{ Percentage } \\
\hline & Questionnaire & Response & & \\
\hline \multirow[t]{2}{*}{1} & \multirow[t]{2}{*}{ Sex } & Male & 30 & $83.3 \%$ \\
\hline & & Female & 6 & $16.7 \%$ \\
\hline \multirow[t]{4}{*}{2} & \multirow[t]{4}{*}{ Age } & $21-30$ & 1 & $2.8 \%$ \\
\hline & & $31-40$ & 23 & $63.3 \%$ \\
\hline & & $41-50$ & 9 & $25 \%$ \\
\hline & & $51-60$ & 3 & $8.3 \%$ \\
\hline \multirow[t]{2}{*}{3} & \multirow[t]{2}{*}{ Marital status } & Single & 1 & $2.8 \%$ \\
\hline & & Married & 35 & $97.2 \%$ \\
\hline \multirow[t]{2}{*}{4} & \multirow[t]{2}{*}{ Educational level } & Can read and write & 12 & $33.3 \%$ \\
\hline & & Cannot read and write & 24 & $66.6 \%$ \\
\hline \multirow[t]{2}{*}{5} & \multirow[t]{2}{*}{ Have own land } & Yes & 36 & $100 \%$ \\
\hline & & No & 0 & $0 \%$ \\
\hline \multirow[t]{3}{*}{6} & \multirow[t]{3}{*}{ Area of farm(ha) } & $<1$ & 13 & $36.1 \%$ \\
\hline & & $1-2$ & 21 & $58.3 \%$ \\
\hline & & $>2$ & 2 & $5.6 \%$ \\
\hline \multirow[t]{3}{*}{7} & \multirow[t]{2}{*}{ Own livestock } & Yes & 27 & $75 \%$ \\
\hline & & No & 9 & $25 \%$ \\
\hline & & Total & 36 & $100 \%$ \\
\hline
\end{tabular}

\section{Source; own survey 2019}

According to the result, the majority $(83.3 \%)$ of the respondents are males and the minority $(16.7 \%)$ are females. Age of the respondents is mostly dominated by the class 31-40 (63.3\%) with the percentage of 2.8, 25, and 8.3 of 21-30, 41-50, and 51-60 age classes', respectively. Most of the respondents (97.2\%) were married, while only the $(2.8 \%)$ of the respondents are single. The educational level of the respondents show that the crop production is dominated by illiterate $(66.6 \%)$ (Cannot read and write), and the minority (33.3\%) of the respondents are literate (can read and write). The results show that all $(100 \%)$ of the respondents own their own land, even if the farm size was generally small. Only few number of farmers (5.6\%) had more than 2 hectares; the other (94.4\%) of farmers with less than two hectares of farmers, with $(36.1 \%)$ of farmers less than one hectare and $(58.3 \%)$ of farmers with 1-2 hectares of farm size. Majority (75\%) of the respondents have livestock while minorities $(25 \%)$ of the respondents do not have livestock.

\subsection{Type of fertilizer the respondents using}

The result showed that the majority $(50 \%)$ of the respondents use both animal manure and commercial fertilizer for food production in integration; while the other $(25 \%)$ of the respondents apply only commercial fertilizer for their whole farm to produce food. The other (25\%) respondents use (animal manure, compost, and commercial fertilizer) $13.9 \%$ and (compost and commercial fertilizer) (11.1\%) in integration. This show that the majority $(75 \%)$ of the respondents use both commercial and organic fertilizers in integration for food production, and the minority $(25 \%)$ of the respondents use only commercial fertilizer with nobody using organic fertilizer alone. 


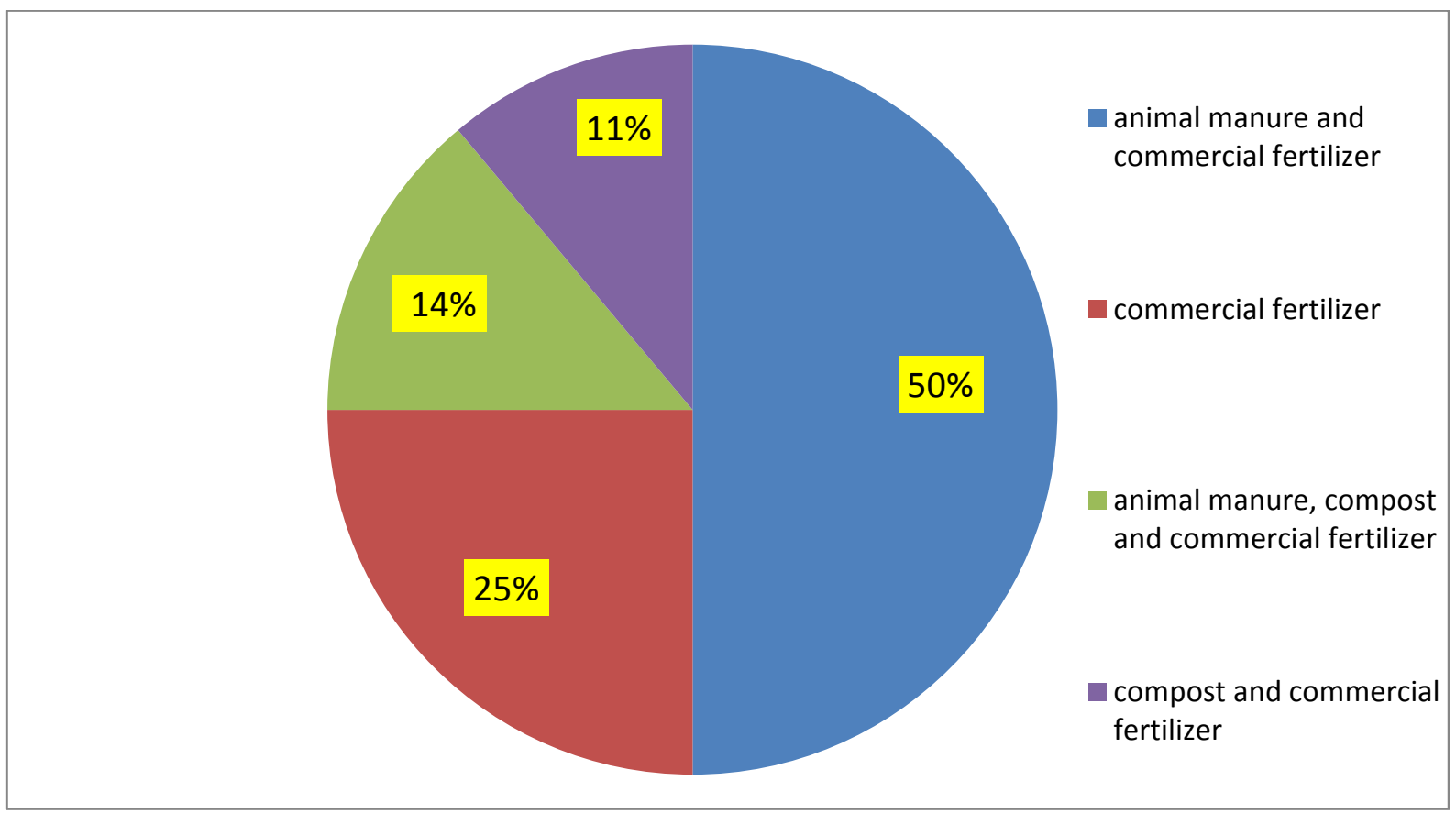

Figure 1: Fertilizer usage of the respondents

\subsection{The system performing}

As presented in the fertilizer usage of the respondents, the majority (27) of the respondents use mixed system of farming (i.e. organic and conventional in integration), while the minority (9) use conventional only. None of the respondents use organic farming alone for food production.

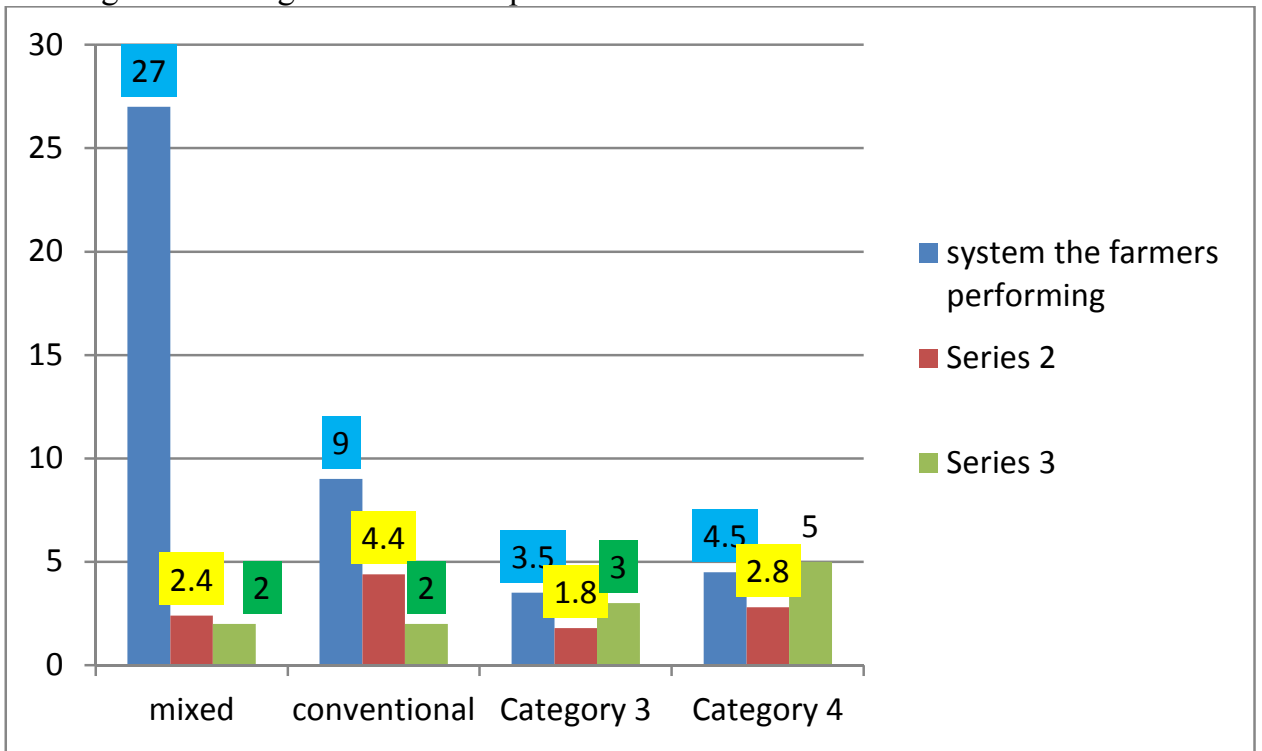

Figure 2: System the respondents performing

\subsection{Reason behind choosing mixed farming system}

The reason why the farmers chosen mixing both organic and conventional farming systems; was evaluated by presenting a list of reason for respondents. The finding revealed that $59.3 \%$ of mixed system using farmers chosen due to three different reasons: to make sustainable food production; to minimize cost of production; and to protect the environment from damage. While the other $40.7 \%$ of the respondents use mixed system using farmers chosen in order to minimize cost of production. 
to make sustainable food production; to minimize cost of production; and to protect the environment from damage

to minimize cost of production

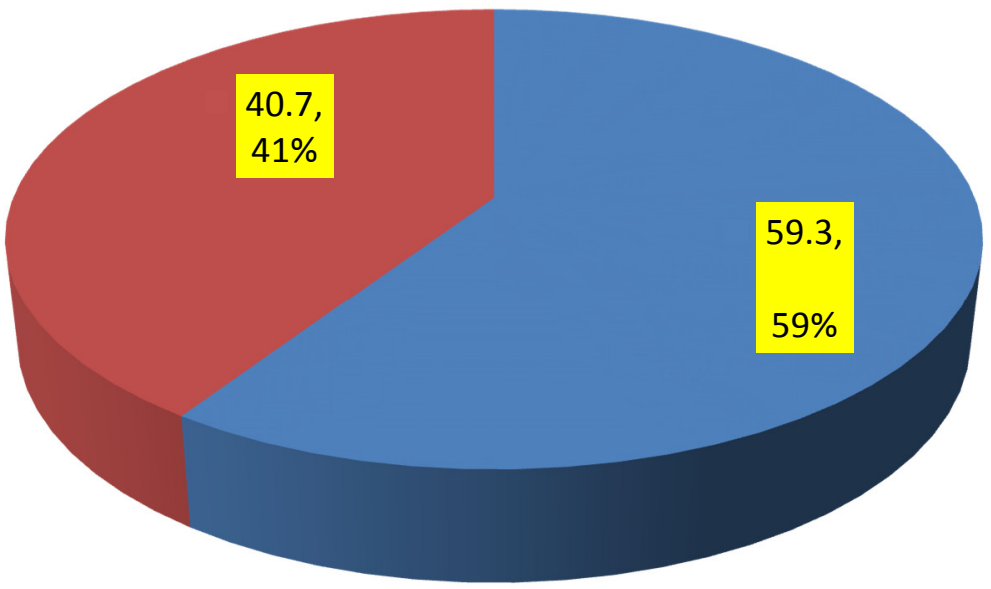

Figure 3: Reasons behind choosing mixed farming system

\subsection{Reason behind choosing conventional farming system}

Since all the respondents use commercial fertilizers either alone or in addition to organic fertilizers, all are asked why they use inorganic fertilizers for their farm. Majority $(52.8 \%)$ of the respondents revealed that they chosen in order to maximize yield per unit of land. But $22.2 \%$ of the respondents chose both due to lack of labor and in order to maximize yield. The other $25 \%$ of the respondents revealed that they chose due to lack of labor $5.6 \%$ and because of external pressure $19.4 \%$.

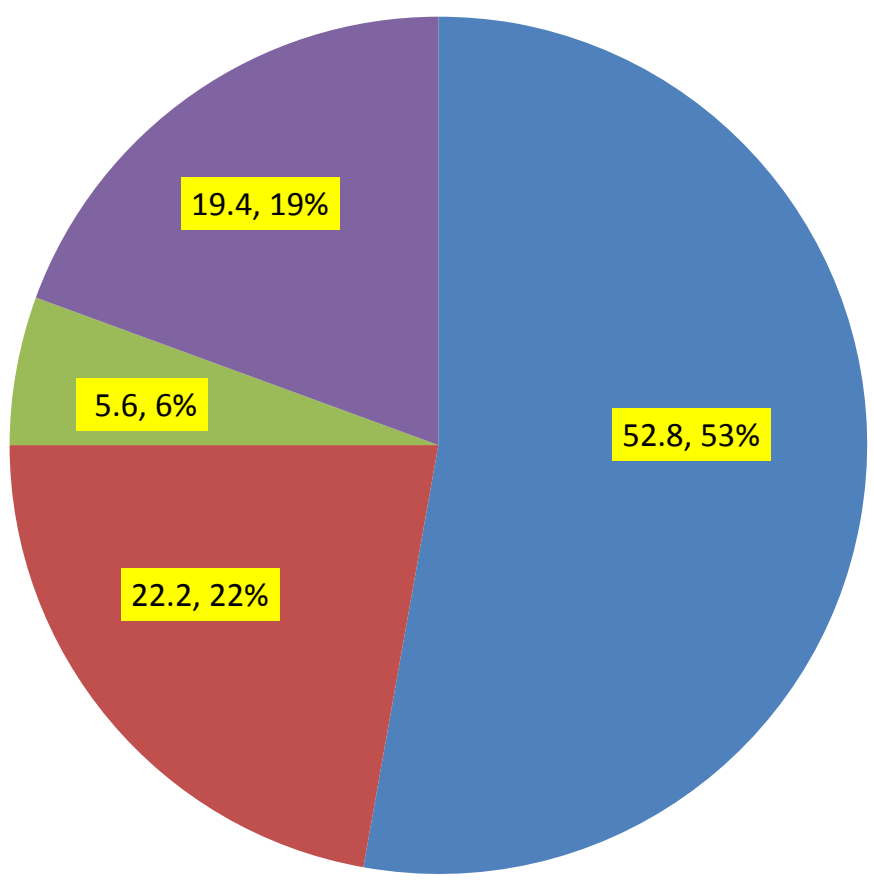

maximize yield per unit of land

due to lack of labor and in order to maximize yield

due to lack of labor

because of external pressure

Figure 4: Reason of respondents to using commercial fertilizers 
4.6. Awareness of respondents towards the advantages and disadvantages of the two farming systems

Table 2: Analysis of respondents' awareness towards the advantages and disadvantages of the two farming systems

\begin{tabular}{|c|c|c|c|c|c|c|c|}
\hline \multirow[t]{2}{*}{ No. } & \multirow[t]{2}{*}{ Questionnaire } & \multicolumn{3}{|c|}{ Response /frequency } & \multicolumn{3}{|c|}{ Percentage (\%) } \\
\hline & & Organic & $\begin{array}{l}\text { Conven } \\
\text { tional }\end{array}$ & $\begin{array}{l}\text { Don't } \\
\text { know/not } \\
\text { sure }\end{array}$ & Organic & conventional & $\begin{array}{l}\text { Don't } \\
\text { know/not } \\
\text { sure }\end{array}$ \\
\hline 1 & Simpler/easier & 2 & 34 & & 5.6 & 94.4 & \\
\hline 2 & $\begin{array}{ll}\text { Enhance } & \text { soil } \\
\text { fertility } & \end{array}$ & 36 & 0 & & 100 & 0 & \\
\hline 3 & $\begin{array}{l}\text { Pollute } \\
\text { environment }\end{array}$ & 1 & 35 & & 2.8 & 97.2 & \\
\hline 4 & $\begin{array}{l}\text { Harm the soil and } \\
\text { other organisms }\end{array}$ & 1 & 35 & & 2.8 & 97.2 & \\
\hline 5 & Good for health & 33 & 0 & 3 & 91.7 & & 8.3 \\
\hline 6 & $\begin{array}{l}\text { Yield more per unit } \\
\text { area }\end{array}$ & $\begin{array}{l}8 \quad \text { (can yield } \\
\text { equal) }\end{array}$ & 28 & & 22.2 & 77.8 & \\
\hline 7 & $\begin{array}{l}\text { Increase income of } \\
\text { farmers }\end{array}$ & $\begin{array}{l}8 \text { (can generate } \\
\text { equal) }\end{array}$ & 28 & & 22.2 & 77.8 & \\
\hline 8 & Require more labor & 36 & 0 & & 100 & 0 & \\
\hline 9 & $\begin{array}{l}\text { Require more input } \\
\text { (in terms of } \\
\text { amount) }\end{array}$ & 36 & 0 & & 100 & 0 & \\
\hline 10 & $\begin{array}{l}\text { Require more cost } \\
\text { of production }\end{array}$ & 0 & 36 & & 0 & 100 & \\
\hline 11 & Sustainable & 36 & 0 & & 100 & 0 & \\
\hline
\end{tabular}

Source own data 2019

As presented on the above table, the farmers' awareness on the advantages and disadvantages of the two farming systems was analyzed by asking farmers on issues which are identified scientifically by various researchers about the advantages and disadvantages of organic and conventional farming systems. Based on the findings, most $(94.4 \%)$ of the respondents revealed that the conventional farming system is easier or simpler to perform than that of organic farming, while $5.6 \%$ of the respondents said organic is simpler than conventional. All the respondents revealed that organic farming system enhances the fertility of the soil more than conventional farming system. And almost all (97.2\%) of the respondents said that conventional farming system pollutes the environment, while $2.8 \%$ said organic pollutes the environment. The vast majority $(91.7 \%)$ of the respondents expressed that the organic farming system is good for health and it is capable of producing healthier products than that of conventional farming system. The farmers awareness of the farming systems towards producing more yield per unit area and increasing the income of the farmers was also dominated by farmers who answered the conventional farming system $77.8 \%$; and the other $22.2 \%$ said that the organic farming system can produce equal yield and generate equal income as the conventional farming if it is managed and implemented properly. All 100\% of the respondents are agreed on that the organic farming system require more labor and more input (in terms of amount) to produce food. All the respondents agreed that the conventional farming system requires more cost of the production to produce agricultural products. At the end, all (100\%) of the respondents revealed that the organic farming system is sustainable than that of conventional farming system.

\section{CONCLUSION AND RECOMMENDATION}

\subsection{Conclusion}

Based on the findings of this study, it can be concluded that most of the farmers are using both organic fertilizers and commercial fertilizers in integration for food production. Most of them are reasonable of choosing the farming system which they are performing. But there are some farmers who are using commercial fertilizer due to external pressure without willing to use it. It is also possible to conclude as almost all of the farmers are aware of the advantages and disadvantages of both organic and conventional farming system. But there is also argument on the yield amount generated from the systems as argued by most scholars (de Ponti et al., 2012; Seufert et al., 2012; Seufert et al., 2012; Badgley et al., 2007). i.e. some farmers say that conventional farming yields more than that of organic farming; while other farmers argue that organic farming can also yield equally as conventional farming if it is managed well. The only thing that the farmers are against the scientific researchers we noticed is the pesticide usage of the farming systems. All of the farmers said that they apply pesticides and herbicides for both of the farming systems, but more for organic; while the scientific researches argue that conventional farming system uses herbicides and pesticides more than organic system (Gabriel et al., 2010; Batáry et al., 2011). The result also 
showed that the farming activity is dominated by men and middle aged farmers.

\subsection{Recommendation}

Based on the conclusions of this study, we made the following recommendations:-

$\checkmark$ Some sort of education should be given as awareness for the farmers, regarding the importance of commercial fertilizers, rather than forcing them to accept it without knowing its benefit.

$\checkmark$ Females and youth should be encouraged to be actively involved in farming activities.

$\checkmark \quad$ Further study should be conducted on areas of yield generation and pesticide usage of the farming systems.

$\checkmark$ Organic farming system should be encouraged through training and other activities, since it is sustainable and has more environmental benefits.

\section{References}

1. Altieri, M. A. 2004. Linking ecologists and traditional farmers in the search for sustainable agriculture. Frontiers in Ecology and the Environment 2(1):35-42.

2. Anand, M., J. Krishnaswamy, A. Kumar, and A. Bali. 2010. Sustaining biodiversity conservation in human-modified landscapes in the Western Ghats: remnant forests matter. Biological Conservation 143(10):2363-2374. http://dx.doi. org/10.1016/j.biocon.2010.01.013

3. Anderson, R. 2005. A multi-tactic approach to manage weed population dynamics in crop rotations.Agronomy.Journal,97(6):1579-1583. http://dx.doi.org/10.2134/agronj2005.0194

4. Bacon, C. M., C. Getz, S. Kraus, M. Montenegro, and K. Holland. 2012. The social dimensions of sustainability and change in diversified farming systems. Ecology and Society 17(4): 41. http://dx.doi.org/10.5751/ES-05226-170441

5. Badgley, C., J. Moghtader, E. Quintero, E. Zakem, M. J. Chappell, K. Aviles-Vazquez, A. Samulon, and I. Perfecto.2007.

6. Barberi, P. 2002. Weed management in organic agriculture: are we addressing the right issues? Weed Research 42 (3):177-193.

7. Batáry, P., A. Báldi, D. Kleijn, and T. Tscharntke. 2011. Landscape-moderated biodiversity effects of agri-environmental management: a meta-analysis. Proceedings of the Royal Society B-Biological Sciences 278(1713):1894-1902. http:// dx.doi.org/10.1098/rspb.2010.1923

8. Bengtsson, J., J. Ahnström, and A. C. Weibull. 2005. The effects of organic agriculture on biodiversity and abundance: a meta-analysis. Journal of Applied Ecology 42(2):261-269. http://dx.doi.org/10.1111/j.1365-2664.2005.01005.x

9. Benton, T. G., J. A. Vickery, and J. S. Wilson. 2003. Farmland biodiversity: is habitat heterogeneity the key? Trends in Ecology \& Evolution 18(4):182-188.

10. Bezdicek, D. F., and D. Granatstein. 1989. Crop rotation efficiencies and biological diversity in farming systems. American Journal of Alternative Agriculture 4(3-4):111-119. http://dx.doi.org/10.1017/S0889189300002927

11. Bhagwat, S. A., K. J. Willis, H. J. B. Birks, and R. J. Whittaker. 2008. Agroforestry: a refuge for tropical biodiversity?Trends in Ecology \& Evolution23(5):261-267.

12. Bianchi, F., C. Booij, and T. Tscharntke. 2006. Sustainable pest regulation in agricultural landscapes: a review on landscape composition, biodiversity and natural pest control. Proceedings of the Royal Society B: Biological Sciences 273 (1595):1715. http://dx.doi.org/10.1098/rspb.2006.3530

13. BKAAO (2009).Bakilo Keble administration Agricultural office, North Shewa, Ethiopia.

14. Brennan, E. B., and N. S. Boyd. 2012. Winter cover crop seeding rate and variety affects during eight years of organic vegetables: II. Cover crop nitrogen accumulation. Agronomy Journal 104(3):799-806. http://dx.doi.org/10.2134/agronj2011.0331

15. Carvalheiro, L. G., R. Veldtman, A. G. Shenkute, G. B. Tesfay, C. W. W. Pirk, J. S. Donaldson, and S. W. Nicolson. 2011. Natural and within-farmland biodiversity enhances crop productivity. Ecology Letters 14(3):251-259. http://dx.doi. org/10.1111/j.1461-0248.2010.01579.x

16. Chaplin-Kramer, R., M. E. O'Rourke, E. J. Blitzer, and C. Kremen, C. 2011. A meta-analysis of crop pest and natural enemy response to landscape complexity. Ecology Letters 14 (9):922-932. http://dx.doi.org/10.1111/j.1461-0248.2011.01642. x

17. Connor, D. J. 2008. Organic agriculture cannot feed the world. Field Crops Research 106(2):187-190. http://dx.doi. org/10.1016/j.fcr.2007.11.010

18. Conyers, M. K., and P. W. Moody. 2009. A conceptual framework for improving the P efficiency of organic farming without inputs of soluble P fertiliser. Crop \& Pasture Science 60(2):100-104. http://dx.doi.org/10.1071/CP06327

19. Crews, T. E., and M. B. Peoples. 2004. Legume versus fertilizer sources of nitrogen: ecological tradeoffs and human needs. Agriculture Ecosystems \& Environment 102 (3):279-297. 
20. Crowder, D. W., T. D. Northfield, M. R. Strand, and M. R. Snyder. 2010. Organic agriculture promotes evenness and natural pest control. Nature 466(7302):109-112. http://dx.doi. org/10.1038/nature09183

21. de Ponti, T., B. Rijk, and M. K. van Ittersum. 2012. The crop yield gap between organic and conventional agriculture.

22. Drinkwater, L., D. Letourneau, F. Workneh, A. Van Bruggen, and C. Shennan. 1995. Fundamental differences between conventional and organic tomato agroecosystems in California. Ecological Applications 5(4):1098-1112. http:// dx.doi.org/10.2307/2269357

23. Ecosystem Functioning, \& Human Wellbeing. Oxford University Press Inc., New York, New York, USA. http://dx. doi.org/10.1093/acprof:oso/9780199547951.003.0013

24. Edmeades, D. C. 2003. The long-term effects of manures and fertilisers on soil productivity and quality: a review. Nutrient Cycling in Agroecosystems 66(2):165-180.

25. Fliessbach, A., H. R. Oberholzer, L. Gunst, and P. Mäder, P. 2007. Soil organic matter and biological soil quality indicators after 21 years of organic and conventional farming. Agriculture, Ecosystems \& Environment 118(1-4):273-284. http://dx.doi.org/10.1016/j.agee.2006.05.022

26. Food and Agricultural Organization (FAO). 2011. The state of food insecurity in the world 2011: how does international price volatility affect domestic economies and food security? United Nations, Rome, Italy.

27. Francis, C. A. 2004. Advances in the design of resourceefficient cropping systems. Pages 15-32 in A. Shrestha, editor. Cropping systems: trends and advances. Food Products Press, Binghamton, New York, USA. http://dx.doi.org/10.1300/J144v08n01_02

28. Franzluebbers, A. J. 2004. Tillage and residue management effects on soil organic matter. Pages 227-268 in F. Magdoff and R. R. Weil, editors. Soil organic matter in sustainable agriculture. CRC Press, Boca Raton, Florida, USA. http://dx. doi.org/10.1201/9780203496374.ch8

29. Fuller, R., L. Norton, R. Feber, P. Johnson, D. Chamberlain, A. Joys, F. Mathews, R. Stuart, M. Townsend, and W. Manley. 2005. Benefits of organic farming to biodiversity vary among taxa. Biology letters 1(4):431. http://dx.doi.org/10.1098/ rsbl.2005.0357

30. Gabriel, D., I. Roschewitz, T. Tscharntke, and C. Thies. 2006. Beta diversity at different spatial scales: plant communities in organic and conventional agriculture. Ecological Applications 16(5):2011-2021. http://dx.doi.org/10.1890/1051-0761(2006) 016[2011:BDADSS]2.0.CO;2

31. Gardner, J. B., and L. E. Drinkwater. 2009. The fate of nitrogen in grain cropping systems: a meta-analysis of N-15 field experiments. Ecological Applications 19(8):2167-2184.

32. Glover, J. D., C. M. Cox, and J. P. Reganold. 2007. Future farming: a return to roots? Scientific American 297:82-89.

33. Gomiero, T., D. Pimentel, and M G. Paoletti. 2011b. Is there a need for a more sustainable agriculture? Critical Reviews in Plant Sciences 30(1):6-23.

34. Green, R. E., S. J. Cornell, J. P. W. Scharlemann, and A. Balmford. 2005. Farming and the fate of wild nature. Science 307(5709):550-555. http://dx.doi.org/10.1126/science.1106049

35. Hauggaard-Nielsen, H., and Jensen, E. S. 2005. Facilitative root interactions in intercrops. Plant and Soil $274(1-2): 237-250$.

36. Holt-Giménez, E. 2002. Measuring farmers' agroecological resistance after Hurricane Mitch in Nicaragua: a case study in participatory, sustainable land management impact monitoring. Agriculture, Ecosystems \& Environment 93 (1-3):87-105. http://dx.doi.org/10.1016/S0167-8809(02)00006-3

37. Holzschuh, A., I. Steffan-Dewenter, D. Kleijn, and T. Tscharntke. 2007. Diversity of flower-visiting bees in cereal fields: effects of farming system, landscape composition and regional context. Journal of Applied Ecology 44(1):41-49. http://dx.doi.org/10.1111/j.1365-2664.2006.01259.x

38. Hudson, B. 1994. Soil organic matter and available water capacity. Journal of Soil and Water Conservation 49 (2):189-194.

39. Iles, A., and R. Marsh. 2012. Nurturing diversified farming systems in industrialized countries: how public policy can contribute. Ecology and Society 17(4): 42. http://dx.doi. org/10.5751/ES-05041-170442

40. Kirchmann, H., L. Bergstrom, T. Katterer, O. Andren, and R. Andersson. 2008. Can organic crop production feed the world? Pages 39-72 in H. Kirchmann and L. Bergstrom, editors. Organic Crop Production - Ambitions and Limitations. Springer Science+Business Media, .

41. Kleijn, D., R. A. Baquero, Y. Clough, M. Diaz, J. De Esteban, F. Fernandez, D. Gabriel, F. Herzog, A. Holzschuh, R. Johl, E. Knop, A., Kruess, E. J. P. Marshall, I. Steffan-Dewenter, T. Tscharntke, J. Verhulst, T. M. West, and J. L. Yela. 2006. Mixed biodiversity benefits of agri-environment schemes in five European countries. Ecology Letters 9(3):243-254. http:// dx.doi.org/10.1111/j.1461-0248.2005.00869.x

42. Kremen, C., A. Iles, and C. Bacon. 2012. Diversified farming systems: an agroecological, systems-based alternative to modern industrial agriculture. Ecology and Society 17(4): 44. http://dx.doi.org/10.5751/ES- 
05103-170444

43. Lal, R. 2004. Soil carbon sequestration impacts on global climate change and food security. Science 304 (5677):1623-1627. http://dx.doi.org/10.1126/science.1097396

44. Lammerts van Bueren, E. T., S. Jones, L. Tamm, K. Murphy, J. Myers, C, Leifert, and M. Messmer. 2011. The need to breed crop varieties suitable for organic farming, using wheat, tomato and broccoli as examples: a review. NJAS-Wageningen Journal of Life Sciences 58(3):193-205. http://dx.doi. org/10.1016/j.njas.2010.04.001

45. Letourneau, D. K., and S. G. Bothwell. 2008. Comparison of organic and conventional farms: challenging ecologists to make biodiversity functional. Frontiers in Ecology and the Environment 6(8):430-438. http://dx.doi.org/10.1890/070081

46. Lipson, M. 1997. Searching for the" O-word": analyzing the USDA current research information system for pertinence to organic farming. Organic Farming Research Foundation, Santa Cruz, California, USA.

47. Lotter, D., R. Seidel, and W. Liebhardt. 2003. The performance of organic and conventional cropping systems in an extreme climate year. American Journal of Alternative Agriculture 18(3):146-154. http://dx.doi.org/10.1079/AJAA200345

48. Mäder, P., A. Fliessbach, D. Dubois, L. Gunst, P. Fried, and U. Niggli. 2002. Soil fertility and biodiversity in organic farming. Science 296(5573):1694. http://dx.doi.org/10.1126/ science.1071148

49. Marriott, E. E., and M. M. Wander. 2006. Total and labile soil organic matter in organic and conventional farming systems. Soil Science Society of America Journal 70(3):950-959. http:// dx.doi.org/10.2136/sssaj2005.0241

50. Mondelaers, K., J. Aertsens, and G. Van Huylenbroeck. 2009. A meta-analysis of the differences in environmental impacts between organic and conventional farming. British Food Journal 111(10):10981119. http://dx.doi.org/10.1108/00070700910992925

51. Organic agriculture and the global food supply. Renewable Agriculture and Food Systems 22(02):86-108 http://dx.doi.org/10.1017/S1742170507001640

52. Phalan, B., M. Onial, A. Balmford, and R. E. Green. 2011. Reconciling food production and biodiversity conservation: land sharing and land sparing compared. Science 333 (6047):1289-1291. http://dx.doi.org/10.1126/science. 1208742

53. Pimentel, D., P. Hepperly, J. Hanson, D. Douds, and R. Seidel. 2005. Environmental, energetic, and economic comparisons of organic and conventional farming systems. Bioscience 55 (7):573-582. http://dx.doi.org/10.1641/0006-3568(2005)055 [0573:EEAECO]2.0.CO;2

54. Reganold, J. P., L. F. Elliott, and Y. L. Unger. 1987. Longterm effects of organic and conventional farming on soil erosion. Nature 330(6146):370-372. http://dx.doi. org/10.1038/330370a0

55. Seufert, V., N. Ramankutty, , and J. A. Foley. 2012. Comparing the yields of organic and conventional agriculture. Nature 485(7397):229-U113. http://dx.doi.org/10.1038/nature11069

56. Sooby, J. 2001. State of the states: organic farming systems research at land grant institutions 2000-2001. Organic Farming Research Foundation, Santa Cruz, California, USA.

57. Tilman, D., K. G. Cassman, P. A. Matson, R. Naylor, and S. Polasky. 2002. Agricultural sustainability and intensive production practices. Nature 418(6898):671-677. http://dx. doi.org/10.1038/nature01014

58. Tscharntke, T., A. M. Klein, A. Kruess, I. Steffan-Dewenter, and C. Thies. 2005. Landscape perspectives on agricultural intensification and biodiversity-ecosystem service management. Ecology Letters 8(8):857-874. http://dx.doi.org/10.1111/ j.1461-0248.2005.00782.x

59. Vallad, G. E., and R. M. Goodman. 2004. Systemic acquired resistance and induced systemic resistance in conventional agriculture. Crop Science 44(6):1920-1934. http://dx.doi. org/10.2135/cropsci2004.1920

60. Weil, R. R., and F. Magdoff. 2004. Significance of soil organic matter to soil quality and health. Pages 1-42 in F. Magdoff and R. R. Weil, editors. Soil organic matter in sustainable agriculture. CRC Press, Boca Raton, Florida, USA. http://dx. doi.org/10.1201/9780203496374.ch1

61. Winqvist, C., J. Bengtsson, T. Aavik, F. Berendse, L. W. Clement, S. Eggers, C. Fischer, A. Flohre, F. Geiger, and J. Liira. 2011. Mixed effects of organic farming and landscape complexity on farmland biodiversity and biological control potential across Europe. Journal of Applied Ecology 48 (3):570-579. http://dx.doi.org/10.1111/j.1365-2664.2010.01950. x

62. Zewde, T., C. Fininsa, P. K. Sakhuja, and S. Ahmed. 2007. Association of white rot (Sclerotium cepivorum) of garlic with environmental factors and cultural practices in the North Shewa highlands of Ethiopia. Crop Protection 26 (10):1566-1573. http://dx.doi.org/10.1016/j.cropro.2007.01.007

63. Zhu, Y., H. Chen, J. Fan, Y. Wang, Y. Li, J. Chen, J. X. Fan, S., Yang, L. Hu, and H. Leung. 2000. Genetic diversity and disease control in rice. Nature 406(6797):718-7

\section{Appendix 1: Questionnaire}

Survey questionnaire on farmers' attitude towards organic and conventional farming systems 


\section{House hold data}

\begin{tabular}{|l|ll|}
\hline Gender & 1. & Male \\
& 2. & Female \\
\hline Age (years) & 1. & Below 20 \\
& 2. & $21-30$ \\
& 3. & $31-40$ \\
& 4. & $41-50$ \\
& 5. & $51-60$ \\
& 6. & Above 60 \\
\hline Education level & 1. & Cannot read and write \\
& 2. & Can read and write \\
\hline Marital status & 1. & Single \\
& 2. & Married \\
& 3. & Divorced \\
& 4. & Others \\
\hline & & \\
\hline
\end{tabular}

\section{Background questions}

1. Do you have your own land?

1. Yes

2. No

2. Do you have livestock?

1. Yes

2. No

3. What area of farm do you have? Area farmed (hec)

4. What type of fertilizer do you use?

1. Crop residue

2. Animal manure

3. Compost

4. Commercial fertilizers 


\section{Questions related to the study}

1. Which system are you performing?
1. Organic farming system
2. Inorganic farming system
3. Mixed

2. Why have you chosen organic farming system? (for farmers who prefer organic farming system)
1 Due to lack of money to buy synthesized fertilizers
2 To make sustainable food production
3 To increase food production
4 To minimize cost of production
5 To protect the environment from damage
6 To produce healthier products
7 Other(explain)

3. Why have you chosen conventional farming system? (for farmers who prefer conventional farming system)

1 To maximize yield per unit area

2 Because of external pressure like agricultural workers and neighbors

3 Due to lack of labor

4 Due to lack of knowledge about organic agriculture

5 Other

(explain).

4. Which system do you think is simpler or easier?
1. Organic
2. Conventional
3. Not sure/don't know

5. Which system do you think uses pesticides/ herbicides?
1. Organic
2. Conventional
3. Not sure/don't know

6. Which system do you think enhance soil fertility?
1. Organic
2. Conventional
3. Not sure/don't know

7. Which system do you think pollute environment and other organisms?
1. Organic
2. Conventional
3. Not sure/don't know

8. Which system do you think harm the soil and other organisms?
1. Organic
2. Conventional
3. Not sure/don't know

9. Which system do you think is good for health?
1. Organic
2. Conventional
3. Not sure/don't know

10. Which system do you think yields more per unit of land?
1. Organic
2. Conventional
3. Not sure/don't know

11. Which system do you think can increase the income of the farmers?
1. Organic
2. Conventional
3. Not sure/don't know

12. Which system do you think requires more labor to produce?
1. Organic
2. Conventional
3. Not sure/don't know 
13. Which system do you think require more input for production (not in cost in terms of amount)?
1. Organic
2. Conventional
3. Not sure/don't know

14. Which system do you think require more cost of production? (in terms of cost of inputs)

1. Organic

2. Conventional

3. Not sure/don't know

15. Which system do you think is sustainable?

1. Organic

2. Conventional

3. Not sure/don't know 